\title{
PEMANFAATAN ANALISIS BIAYA VOLUME LABA SEBAGAI ALAT DALAM PERENCANAAN LABA PADA PT INKO JAVA SEMARANG
}

\author{
Syafira Rosyalia, Lardin Korawijayanti*, Hartono \\ Politeknik Negeri Semarang, Jl. Prof. H Soedarto SH Tembalang Semarang \\ Email: syafira.rosyalia15@gmail.com
}

\begin{abstract}
Cost profit volume analysis is a tool used by management to do a shortterm profit planning by using an approach to costs, volume of sales, and profits. The purpose of its research is to determine the application of the analysis of cost volume profit at PT Inko Java Semarang in profit planning with the calculation of contribution margin, contribution margin ratio, break-even point, the analysis of the profit target, margin of safety, degree of operating leverage, shut down point, and sensitivity analysis. Data that used in this final project is secondary data consist of the sales and costs data in 2017. Data collection was obtained by interview and documentation. The writing method thatused are description and exposition method. The results of this research showed that break-even point was at the sales value of $R p$ 51.560.373.141,52 or 148.868 units with an average contribution margin per unit of $R p$ 41.217,04and contribution margin ratio amounted to 11,90\%. The profit target set at $1 \%$ of the sales in 2017. To reach the expeceted profit, the volume of sales must be $R p$ 55.520.899.913. Margin of safety are $R p$ 3.960.526.771,48or by 7,13\% and the degree of operating leverage amounted to 11,90. Shut down point occurs at the level of sales of $R p$ 45.823.939.568,56.
\end{abstract}

Keywords: Profit Planning, Cost Volume Profit, Break-Even Analysis, Contribution Margin, PT Inko Java Semarang.

Abstrak: Analisis biaya volume laba merupakan alat yang digunakan manajemen dalam melakukan perencanaan laba jangka pendek dengan menggunakan pendekatan terhadap biaya, volume penjualan, dan laba. Penelitian ini bertujuan untuk mengetahui penerapan analisis biaya volume laba pada PT Inko Java Semarang dalam merencanakan laba dengan melakukan perhitungan terhadap kontribusi margin, rasio kontribusi margin, titik impas (break even point), analisa target laba, batas keamanan (margin of safety), tingkat pengungkit operasi (degree of operating leverage), titik penutupan usaha (shut down point), dan analisis sensitivitas. Data yang digunakan adalah data sekuder berupa data penjualan serta data biaya yang terjadi selama tahun 2017. Pengumpulan data diperoleh dengan cara wawancara dan dokumentasi. Metode penulisan yang digunakan adalah deskripsi dan eksposisi. Hasil penelitian ini menunjukkan bahwa titik impas berada pada nilai penjualan $\mathrm{Rp} 51.560 .373 .141,52$ atau sebanyak 148.868 unit dengan kontribusi margin rata-rata per unit sebesar $\mathrm{Rp} 41.217,04$ dan rasio kontribusi margin sebesar $11,90 \%$. Laba yang ditetapkan sebesar $1 \%$ dari penjualan tahun 2017, sehingga untuk mencapai laba yang diinginkan, penjualan ditargetkan sebesar $R p$ 55.520.899.913. Batas pengaman diketahui senilaiRp 3.960.526.771,48 atau sebesar $7,13 \%$ dan tingkat pengungkit operasi sebesar 11,90. Titik penutupan usaha terjadi pada tingkat penjualan Rp 45.823.939.568,56.

Kata Kunci: Perencanaan Laba, Biaya Volume Laba, Analisis Titik Impas, Kontribusi Margin, PT Inko Java Semarang. 


\section{PENDAHULUAN}

\section{Latar Belakang Masalah}

Tujuan utama didirikan perusahaan adalah untuk memperoleh laba. Laba seringkali dijadikan tolok ukur untuk menilai prestasi dan kesuksesan suatu perusahaan. Pihak manajemen harus dapat mengambil langkah tepat dan strategis guna mencapai tujuan utama perusahaan tersebut. Langkah yang dapat diambil oleh manajemen dalam mencapai tingkat laba yang optimal menurut Budiwibowo (2012) adalah menekan biaya operasional serendah mungkin (melakukan efisiensi) dengan mempertahankan tingkat harga dan volume penjualan yang ada, menentukan tingkat harga jual sedemikian rupa sesuai dengan laba yang dikehendaki, dan meningkatkan volume penjualan sebesar mungkin. Ketiga langkah tersebut merupakan suatu kesatuan yang tidak dapat dipisahkan karena memiliki keterikatan satu sama lain. Langkah tersebut merupakan langkah perencanaan untuk dapat mencapai tujuan perusahaan.

Perencanaan merupakan salah satu faktor yang sangat berperan penting dalam suatu perusahaan karena akan berpengaruh secara langsung terhadap faktor kelancaran maupun keberhasilan manajemen dalam mencapai tujuannya.Dalam hal kaitannya untuk mencapai tingkat laba optimal, manajemen dapat menggunakan sebuah perencanaan yang disebut dengan perencanaan laba. Perencanaan laba berisikan langkahlangkah yang ditempuh perusahaan untuk mencapai besarnya target laba yang diinginkan. Laba merupakan selisih antara pendapatan yang diterima dari penjualan dengan biaya yang dikeluarkan. Alat bantu yang tepat untuk digunakan dalam perencanaan laba adalah Analisis Biaya Volume Laba (BVL). Arizal et al (2014) dalam penelitiannya menyatakan bahwa teknik analisis pengelolaan hubungan antara biaya, volume, dan laba merupakan kunci dalam menjaga kelangsungan hidup perusahaan dan mengembangkan aktivitas perusahaan karena informasi yang dihasilkan dapat digabungkan untuk menentukan arah aktivitas perusahaan seperti jumlah produksi yang dihasilkan untuk memperoleh laba yang diinginkan.

Analisis Biaya Volume Laba merupakan sebuah alat untuk mempelajari hubungan antara biaya total, volume penjualan, pendapatan total, dan laba agar dapat membantu perencanaan laba jangka pendek (Kusuma et al, 2013:123). Analisis Biaya Volume Laba berfokus pada berbagai faktor yang mempengaruhi perubahan dalam komponen laba. Analisis ini menekan keterkaitan antara biaya, kuantitas yang terjual, dan harga, serta semua informasi keuangan perusahaan terkandung di dalamnya, sehingga dapat menjadi alat yang bermanfaat untuk mengidentifikasi cakupan dan besarnya kesulitan ekonomi yang dihadapi perusahaan (Hansen dan Mowen, 2009). Sedangkan menurut Garrison et al (2013:208) Analisis BVL berfokus pada pengaruh atas kelima faktor terhadap laba yaitu, 1) Harga produk, 2) Volume penjualan, 3) Biaya variabel per unit, 4) Total biaya tetap, dan 5) Bauran produk yang dijual, sehingga membantu manajemen memahami pengaruh faktor-faktor tersebut terhadap laba. Iswara dan Susanti (2017) menjabarkan kelima faktor tersebut sebagai berikut: 1) Harga produk yaitu harga yang ditetapkan di dalam suatu periode tertentu secara konstan, 2) Volume atau tingkat aktivitas yaitu besarnya produk yang dihasilkan dan direncanakan akan dijual di dalam suatu periode tertentu, 3) Biaya variabel per unit yaitu besarnya biaya produk yang dibebankan secara langsung pada setiap unit barang yang diproduksi, 4) Total biaya tetap yaitu keseluruhan biaya periodik di dalam suatu periode tertentu, dan 5) Bauran volume produk yang dijual yaitu proporsi volume relatif produk-produk perusahaan yang akan dijual. 
Untuk mengetahui hubungan antara pendapatan, biaya, dan laba terhadap perubahan volume penjualan adalah dengan menentukan titik impas perusahaan. Titik impas ini merupakan salah satu aspek penting dalam Analisis Biaya Volume Laba. Titik Impas (Break Even Point, BEP) adalah titik dimana total pendapatan sama dengan total biaya, titik dimana laba sama dengan nol (Hansen dan Mowen, 2009:4). Sehingga, dengan melakukan analisis titik impas, manajemen akan memperoleh informasi terkait tingkat penjualan minimum yang harus dicapai perusahaan agar tidak mengalami kerugian. Manajemen dapat membuat perencanaan mengenai seberapa besar penjualan yang harus dicapai untuk mencapai tingkat laba yang diinginkan, dan juga untuk mengetahui seberapa besar penurunan penjualan yang terjadi sebelum mengalami kerugian. Sehubungan dengan hal tersebut, pimpinan perusahaan dapat mengetahui kemungkinan yang terjadi pada perusahaannya kedepan, apabila perusahaan mencapai tingkat penjualan dibawah titik impas, maka diharapkan dapat diketahui penyebab terjadinya penurunan tersebut.

Hal lain yang tak kalah penting dalam Analisis Biaya Volume Laba ialah memahami konsep biaya (biaya tetap dan biaya variabel) karena erat kaitannya dengan penjualan dan laba. Selain hal-hal di atas, Analisis Biaya Volume Laba juga menyediakan data mengenai margin kontribusi dan rasio margin kontribusi, margin pengaman (Margin of Safety), tingkat Laverage Operasi, titik penutupan perusahaan (Shut Down Point), dan analisis target laba, serta memungkinkan manajemen dalam melakukan analisis sensitifitas untuk menguji dampak perubahan biaya dan harga jual terhadap laba.

PT Inko Java Semarang merupakan perusahaan manufaktur yang terletak di Jl. Raya PTP. XVIII., Karangjati, Bergas, Semarang yang melakukan kegiatan dalam bidang produksi alat olahraga yaitu sarung tangan baseball dan softball untuk dieksport ke Amerika. PT Inko Java memiliki tiga anak perusahaan yang masing-masing berada di Osaka Jepang, Busan Korea Selatan, dan Los Angeles California Amerika Serikat. Dalam menjalankan usahanya, PT Inko Java Semarang belum membuat perencanaan laba dengan metode biaya volume laba sehingga perencanaan laba yang dilakukan belum terlalu detail seperti menentukan seberapa besar tingkat penjualan yang ingin dicapai pada periode berikutnya untuk memperoleh laba yang diinginkan, seberapa besar penurunan penjualan yang boleh terjadi agar tidak mengalami kerugian, seberapa besar laba yang diperoleh apabila tejadi peningkatan penjualan, dan yang lainnya.

Mengingat pentingnya Analisis
Biaya Volume Laba dalam perencanaan laba bagi perusahaan untuk mencapai tujuan utama perusahaan yaitu memperoleh laba secara optimal, perlu dilakukan.

\section{Rumusan Masalah}

PT Inko Java Semarang merupakan perusahaan manufaktur yang melakukan kegiatan dalam bidang produksi alat olahraga yaitu sarung tangan baseball dan softball yang telah memiliki tiga anak cabang yang masing-masing berada di Osaka Jepang, Busan Korea Selatan, dan Los Angeles California Amerika Serikat dengan keuntungan yang sudah lumayan besar. Berdasarkan latar belakang diatas, diketahui bahwa PT Inko Java Semarang belum pernah membuat perencanaan laba dengan menggunakan analisis biaya volume laba, sehingga manajemen perlu mengetahui faktor-faktor yang terkait dengan laba. Dalam membuat perencanaan laba, digunakan data PT Inko Java Semarang tahun 2017 sebagai tahun acuan. Berdasarkan uraian di atas dapat disusun rumusan masalah sebagai berikut:

\begin{tabular}{lllr} 
a. & Bagaimana & \multicolumn{2}{c}{ penyusunan } \\
perencanaan & laba & dengan \\
menggunakan & Analisis & Biaya
\end{tabular}


Volume Laba pada PT Inko Java Semarang?

b. Seberapa besar tingkat penjualan yang harus dicapai untuk memperoleh tingkat laba yang diinginkan?

\section{METODE}

Metode pengumpulan data yang digunakan dalam penelitian ini adalah metode wawancara dan metode dokumentasi. Wawancara dilakukan dengan mengajukan pertanyaan langsung kepada pengelola PT Inko Java Semarang untuk memperoleh informasi mengenai perusahaan dan hal-hal yang berkaitan dengan pencatatan pendapatan dan biaya yang terjadi dalam perusahaan. Dokumentasi dilakukan dengan meminta dokumen-dokumen yang terkait dalam Perencanaan Laba dengan Analisis Biaya Volume Laba pada PT Inko Java Semarangseperti rincian penjualan tahun 2017, data biaya tahun 2017, dan data lainnya seperti gambaran umum perusahaan.

$$
\text { Metode penulisan yang }
$$

digunakan adalah metode deskripsi dan metode eksposisi. Metode deskripsi digunakan untuk memaparkan kegiatan usaha yang dilakukan oleh perusahaan, struktur organisasi, serta deskripsi jabatan pada PT Inko Java Semarang. Metode eksposisi digunakan untuk memaparkan hasil analisis biaya volume laba pada PT Inko Java Semarang.

Tahapan analisis data yang akan dilakukan dalam penyusunan Tugas Akhir ini adalah sebagai berikut:

a. Pengklasifikasian biaya kedalam biaya tetap dan biaya variabel. Untuk biaya campuran/ semivariabel dilakukan pemisahan ke elemen biaya tetap dan biaya variabel yang terkandung didalamnya.

b. Perhitungan Margin Kontribusi dan Rasio Margin Kontribusi.

c. Analisis Titik Impas (Break Even Point).

d. Perhitungan Target Laba tahun 2018. e. Perhitungan Batas Keamanan (Margin of Safety).

f. Perhitungan Tingkat Operating Leverage.

g. Perhitungan Titik Penutupan Usaha (Shut Down Point).

\section{HASIL DAN PEMBAHASAN}

Produk PT Inko Java Semarang

Terdapat beberapa produk yang ada pada PT Inko Java Semarang meliputi Baseball Gloves, Batting Gloves, Defense Gloves, dan Baseball Bag.

\section{Komposisi Penjualan}

Tingkat pejualan paling banyak yaitu produk Baseball Gloves sebesar 99,46\% atau Rp 47.130.577.833untuk sales mix (nilai penjualan) dan $96,44 \%$ atau 136.078 untuk sales mix (unit terjual). Sehingga pembahasan pada Tugas Akhir ini difokuskan pada produk Baseball Gloves.

\section{Komposisi Penjualan Baseball Gloves}

Baseball Gloves terdiri dari berbagai macam tipe. Sehingga komposisi penjualannya sebagai berikut:

Tabel 1. Komposisi Penjualan Baseball Gloves

\begin{tabular}{llrr}
\hline No & $\begin{array}{c}\text { Brand Baseball } \\
\text { Gloves }\end{array}$ & $\begin{array}{c}\text { Sales Mix } \\
\text { (Unit) }\end{array}$ & $\begin{array}{c}\text { Sales Mix } \\
\text { (Nilai Jual) }\end{array}$ \\
\hline 1 & Easton & $72,86 \%$ & $62,97 \%$ \\
2 & Wilson & $13,66 \%$ & $21,03 \%$ \\
3 & IKJ & $8,08 \%$ & $10,13 \%$ \\
4 & David & $1,81 \%$ & $2,68 \%$ \\
5 & Buckler & $1,25 \%$ & $1,21 \%$ \\
6 & Franklin & $1,52 \%$ & $1,06 \%$ \\
7 & Bradley & $0,82 \%$ & $0,92 \%$ \\
\hline & TOTAL & $\mathbf{1 0 0 , 0 0 \%}$ & $\mathbf{1 0 0 , 0 0 \%}$ \\
\hline
\end{tabular}

Sumber: Data Sekunder yang diolah, 2018 


\section{Klasifikasi Biaya}

Dalam menganalisis biaya volume laba, sangat diperlukan untuk mengetahui pembagian /pengkasifikasian biaya ke dalam biaya Berikut merupakan biaya yang dikeluarkan oleh PT Inko Java Semarang Tahun 2017: tetap, biaya variabel, dan memisahkan biaya semivariabel ke biaya tetap dan biaya variabel.

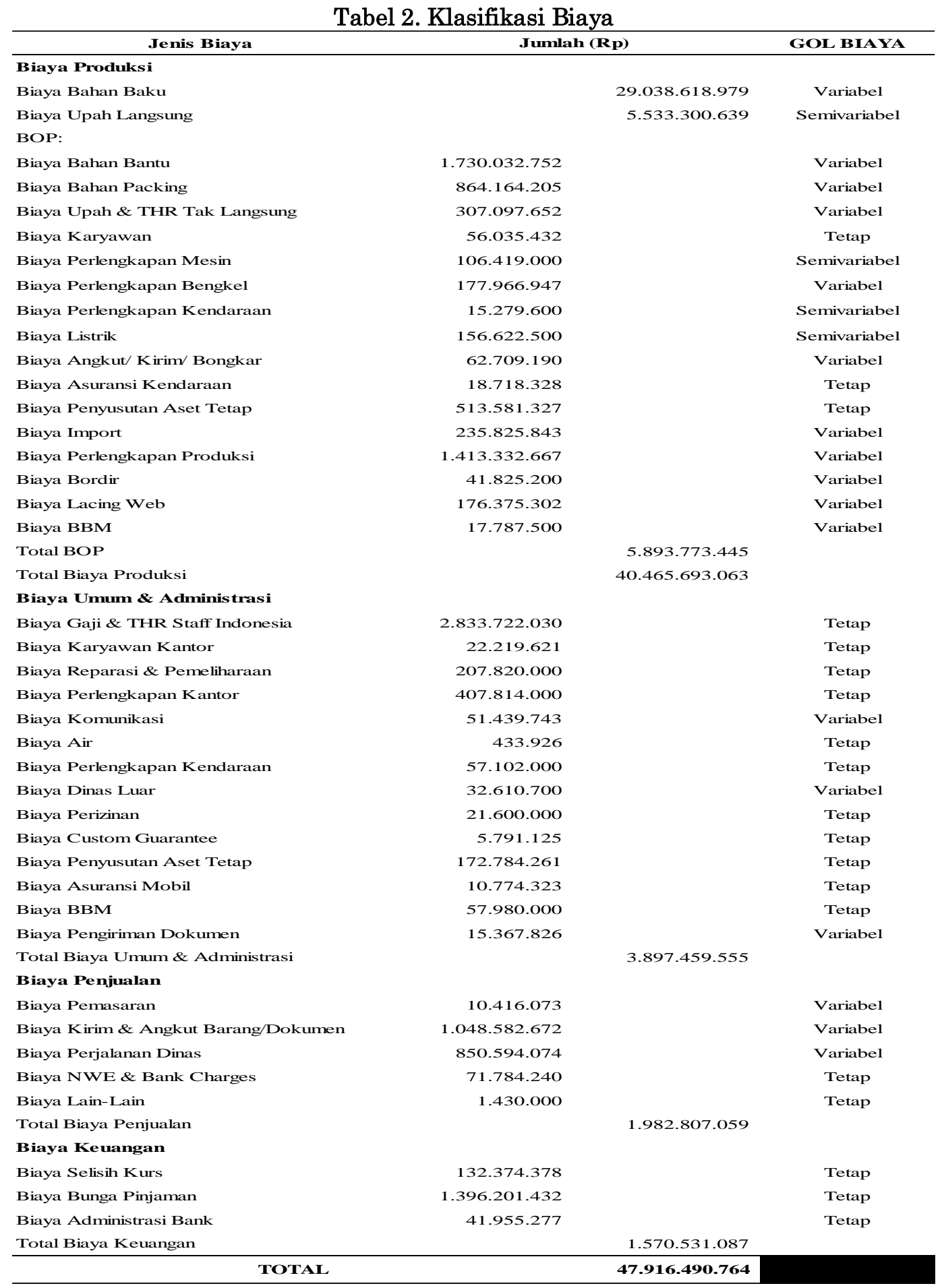

Sumber: Data Sekunder yang diolah, 2018 


\section{Pemisahan Biaya Semivariabel}

Metode yang digunakan dalam pemisahan biaya semivariabel pada PT Inko Java Semarang adalah metode regresi kuadrat terkecil. Metode ini adalah metode estimasi unsur variabel dan tetap biaya campuran dengan meregresi aktivitas terhadap biaya aktivitas tersebut. Metode ini mengasumsikan bahwa hubungan antara aktivitas dan biaya bersifat linear. Metode ini merupakan metode yang akurat karena setiap titik data aktivitas dan biaya aktivitas dipertimbangkan dalam menentukan unsur biaya variabel dan biaya tetap. Persamaan regresi dalam metode regresi kuadrat terkecil adalah $\mathrm{Y}=\mathrm{a}+\mathrm{bX}$. Sedangkan untuk variabel dapat menggunakan formula sebagai berikut:

$$
\begin{aligned}
& \mathrm{b}=\frac{\left(\mathrm{N} \times \sum \mathrm{XY}\right)-\left(\sum \mathrm{X} \times \sum \mathrm{Y}\right)}{\mathrm{N} \sum \mathrm{X}^{2}-\left(\sum \mathrm{X}\right)^{2}} \\
& \mathrm{a}=\frac{\sum \mathrm{Y}-\mathrm{b} \sum \mathrm{X}}{\mathrm{N}}
\end{aligned}
$$

Keterangan:

$$
\begin{aligned}
& \mathrm{a}=\text { Konstanta }(\text { Biaya Tetap) } \\
& \mathrm{b}=\text { Koefisien (Biaya Variabel) } \\
& \mathrm{Y}=\text { Biaya Campuran } \\
& \mathrm{X}=\text { Aktivitas }
\end{aligned}
$$

$\mathrm{N}$ = Jumlah Pengamatan

Tabel 3 menyajikan rincian biaya pada

\begin{tabular}{|c|c|c|c|}
\hline Jenis Biaya & Biaya Tetap & Biaya Variabel & Total Biaya \\
\hline \multicolumn{4}{|l|}{ Biaya Produksi } \\
\hline Biaya Bahan Baku & - & $29.038 .618 .979,00$ & $29.038 .618 .979,00$ \\
\hline Biaya Upah Langsung & $93.600 .000,00$ & $5.439 .700 .639,00$ & $5.533 .300 .639,00$ \\
\hline \multicolumn{4}{|l|}{ BOP: } \\
\hline Biaya Bahan Bantu & - & $1.730 .032 .752,00$ & $1.730 .032 .752,00$ \\
\hline Biaya Bahan Packing & - & $864.164 .205,00$ & $864.164 .205,00$ \\
\hline Biaya Upah \& THR Tak Langsung & - & $307.097 .652,00$ & $307.097 .652,00$ \\
\hline Biaya Karyawan & $56.035 .432,00$ & - & $56.035 .432,00$ \\
\hline Biaya Perlengkapan Mesin & $40.490 .689,66$ & $65.928 .310,34$ & $106.419 .000,00$ \\
\hline Biaya Perlengkapan Bengkel & - & 177.966.947,00 & $177.966 .947,00$ \\
\hline Biaya Perlengkapan Kendaraan & $4.565 .277,74$ & $10.714 .322,26$ & $15.279 .600,00$ \\
\hline Biaya Listrik & $432.762,51$ & $156.189 .737,49$ & $156.622 .500,00$ \\
\hline Biaya Angkut/ Kirim/ Bongkar & - & $62.709 .190,00$ & $62.709 .190,00$ \\
\hline Biaya Asuransi Kendaraan & $18.718 .328,00$ & - & $18.718 .328,00$ \\
\hline Biaya Penyusutan Aset Tetap & $513.581 .327,00$ & - & $513.581 .327,00$ \\
\hline Biaya Import & - & $235.825 .843,00$ & $235.825 .843,00$ \\
\hline Biaya Perlengkapan Produksi & - & $1.413 .332 .667,00$ & $1.413 .332 .667,00$ \\
\hline Biaya Bordir & - & $41.825 .200,00$ & $41.825 .200,00$ \\
\hline Biaya Lacing Web & - & $176.375 .302,00$ & $176.375 .302,00$ \\
\hline Biaya BBM & - & 17.787.500,00 & 17.787.500,00 \\
\hline Total BOP & $633.823 .816,91$ & $5.259 .949 .628,09$ & $5.893 .773 .445,00$ \\
\hline Total Biaya Produksi & $727.423 .816,91$ & $39.738 .269 .246,09$ & $40.465 .693 .063,00$ \\
\hline \multicolumn{4}{|l|}{ Biaya Umum \& Administrasi } \\
\hline Biaya Gaji \& THR Staff Indonesia & $2.833 .722 .030,00$ & - & $2.833 .722 .030,00$ \\
\hline Biaya Karyawan Kantor & $22.219 .621,00$ & - & $22.219 .621,00$ \\
\hline Biaya Reparasi \& Pemeliharaan & $207.820 .000,00$ & - & $207.820 .000,00$ \\
\hline Biaya Perlengkapan Kantor & $407.814 .000,00$ & - & $407.814 .000,00$ \\
\hline Biaya Komunikasi & - & $51.439 .743,00$ & $51.439 .743,00$ \\
\hline Biaya Air & $433.926,00$ & - & $433.926,00$ \\
\hline Biaya Perlengkapan Kendaraan & $57.102 .000,00$ & - & $57.102 .000,00$ \\
\hline Biaya Dinas Luar & - & $32.610 .700,00$ & $32.610 .700,00$ \\
\hline Biaya Perizinan & $21.600 .000,00$ & - & $21.600 .000,00$ \\
\hline Biaya Custom Guarantee & $5.791 .125,00$ & - & $5.791 .125,00$ \\
\hline Biaya Penyusutan Aset Tetap & $172.784 .261,00$ & - & $172.784 .261,00$ \\
\hline Biaya Asuransi Mobil & $10.774 .323,00$ & - & $10.774 .323,00$ \\
\hline Biaya BBM & $57.980 .000,00$ & - & $57.980 .000,00$ \\
\hline Biaya Pengiriman Dokumen & - & $15.367 .826,00$ & $15.367 .826,00$ \\
\hline $\begin{array}{l}\text { Total Biaya Umum \& Administrasi } \\
\text { Biaya Penjualan }\end{array}$ & $3.798 .041 .286,00$ & $99.418 .269,00$ & $3.897 .459 .555,00$ \\
\hline Biaya Pemasaran & - & $10.416 .073,00$ & $10.416 .073,00$ \\
\hline Biaya Kirim \& Angkut Barang/Dokumen & - & $1.048 .582 .672,00$ & $1.048 .582 .672,00$ \\
\hline Biaya Perjalanan Dinas & - & $850.594 .074,00$ & $850.594 .074,00$ \\
\hline Biaya NWE \& Bank Charges & $71.784 .240,00$ & - & $71.784 .240,00$ \\
\hline Biaya Lain-Lain & $1.430 .000,00$ & - & $1.430 .000,00$ \\
\hline Total Biaya Penjualan & $73.214 .240,00$ & $1.909 .592 .819,00$ & $1.982 .807 .059,00$ \\
\hline Biaya Ke uangan & & & \\
\hline Biaya Selisih Kurs & $132.374 .378,00$ & - & $132.374 .378,00$ \\
\hline Biaya Bunga Pinjaman & $1.396 .201 .432,00$ & - & $1.396 .201 .432,00$ \\
\hline Biaya Administrasi Bank & $41.955 .277,00$ & - & $41.955 .277,00$ \\
\hline Total Biaya Keuangan & $1.570 .531 .087,00$ & - & $1.570 .531 .087,00$ \\
\hline TOTAL & $6.169 .210 .429,91$ & 41.747.280.334,09 & 47.916.490.764,00 \\
\hline
\end{tabular}
PT Inko Java Semarang tahun 2017 setelah adanya pemisahan biaya semivariabel beserta klasifikasinya: menentukan biaya tetap dan biaya

Tabel 3. Rincian Biaya Setelah adanya Pemisahan Biaya Semivariabel 
Sumber: Data Sekunder yang diolah, 2018

Komposisi penjualan pada PT Inko Java terbanyak yaitu produk Baseball Gloves sebesar 99,46\%. Oleh karena itu biaya yang dikeluarkan

\section{Tabel 4. Rincian Biaya untuk Produk Baseball Gloves}

\begin{tabular}{|c|c|c|c|}
\hline \multirow{2}{*}{ Jenis Biaya } & \multirow{2}{*}{$\begin{array}{c}\text { Biaya Tetap } \\
99,46 \% \\
\end{array}$} & \multirow{2}{*}{$\begin{array}{c}\text { Biaya Variabel } \\
99,46 \% \\
\end{array}$} & \multirow{2}{*}{$\begin{array}{c}\text { Total Biaya } \\
99,46 \% \\
\end{array}$} \\
\hline & & & \\
\hline \multicolumn{4}{|l|}{ Biaya Produksi } \\
\hline Biaya Bahan Baku & - & $28.881 .810 .436,51$ & $28.881 .810 .436,51$ \\
\hline \multicolumn{3}{|l|}{ BOP: } & $5.503 .420 .815,55$ \\
\hline Biaya Bahan Bantu & - & $1.720 .690 .575,14$ & $1.720 .690 .575,14$ \\
\hline Biaya Bahan Packing & - & $859.497 .718,29$ & $859.497 .718,29$ \\
\hline Biaya Upah \& THR Tak Langsung & - & $305.439 .324,68$ & $305.439 .324,68$ \\
\hline Biaya Karyawan & $55.732 .840,67$ & - & $55.732 .840,67$ \\
\hline Biaya Perlengkapan Mesin & $40.272 .039,93$ & $65.572 .297,47$ & $105.844 .337,40$ \\
\hline Biaya Perlengkapan Bengkel & - & $177.005 .925,49$ & $177.005 .925,49$ \\
\hline Biaya Perlengkapan Kendaraan & $4.540 .625,24$ & $10.656 .464,92$ & 15.197.090,16 \\
\hline Biaya Listrik & $430.425,59$ & $155.346 .312,91$ & $155.776 .738,50$ \\
\hline Biaya Angkut/ Kirim/ Bongkar & - & $62.370 .560,37$ & $62.370 .560,37$ \\
\hline Biaya Asuransi Kendaraan & $18.617 .249,03$ & - & $18.617 .249,03$ \\
\hline Biaya Penyusutan Aset Tetap & $510.807 .987,83$ & - & $510.807 .987,83$ \\
\hline Biaya Import & - & $234.552 .383,45$ & $234.552 .383,45$ \\
\hline Biaya Perlengkapan Produksi & - & $1.405 .700 .670,60$ & $1.405 .700 .670,60$ \\
\hline Biaya Bordir & - & $41.599 .343,92$ & $41.599 .343,92$ \\
\hline Biaya Lacing Web & - & $175.422 .875,37$ & $175.422 .875,37$ \\
\hline Biaya BBM & - & $17.691 .447,50$ & $17.691 .447,50$ \\
\hline Total BOP & $630.401 .168,29$ & $5.231 .545 .900,10$ & $5.861 .947 .068,40$ \\
\hline Total Biaya Produksi & $723.495 .728,29$ & 39.523.682.592,17 & $40.247 .178 .320,46$ \\
\hline \multicolumn{4}{|l|}{ Biaya Umum \& Administrasi } \\
\hline Biaya Gaji \& THR Staff Indonesia & $2.818 .419 .931,04$ & - & $2.818 .419 .931,04$ \\
\hline Biaya Karyawan Kantor & $22.099 .635,05$ & - & $22.099 .635,05$ \\
\hline Biaya Reparasi \& Pemeliharaan & 206.697.772,00 & - & 206.697.772,00 \\
\hline Biaya Perlengkapan Kantor & $405.611 .804,40$ & - & $405.611 .804,40$ \\
\hline Biaya Komunikasi & - & $51.161 .968,39$ & $51.161 .968,39$ \\
\hline Biaya Air & $431.582,80$ & - & $431.582,80$ \\
\hline Biaya Perlengkapan Kendaraan & $56.793 .649,20$ & - & $56.793 .649,20$ \\
\hline Biaya Dinas Luar & - & $32.434 .602,22$ & $32.434 .602,22$ \\
\hline Biaya Perizinan & $21.483 .360,00$ & - & $21.483 .360,00$ \\
\hline Biaya Custom Guarantee & $5.759 .852,93$ & - & $5.759 .852,93$ \\
\hline Biaya Penyusutan Aset Tetap & $171.851 .225,99$ & - & $171.851 .225,99$ \\
\hline Biaya Asuransi Mobil & 10.716.141,66 & - & 10.716.141,66 \\
\hline Biaya BBM & $57.666 .908,00$ & - & $57.666 .908,00$ \\
\hline Biaya Pengiriman Dokumen & - & $15.284 .839,74$ & $15.284 .839,74$ \\
\hline Total Biaya Umum \& Administrasi & $3.777 .531 .863,06$ & $98.881 .410,35$ & $3.876 .413 .273,40$ \\
\hline \multicolumn{4}{|l|}{ Biaya Penjualan } \\
\hline Biaya Pemasaran & - & $10.359 .826,21$ & $10.359 .826,21$ \\
\hline Biaya Kirim \& Angkut Barang/Dokumen & - & $1.042 .920 .325,57$ & $1.042 .920 .325,57$ \\
\hline Biaya Perjalanan Dinas & - & 846.000.866,00 & $846.000 .866,00$ \\
\hline Biaya NWE \& Bank Charges & $71.396 .605,10$ & - & $71.396 .605,10$ \\
\hline Biaya Lain-Lain & $1.422 .278,00$ & - & $1.422 .278,00$ \\
\hline Total Biaya Penjualan & $72.818 .883,10$ & $1.899 .281 .017,78$ & $1.972 .099 .900,88$ \\
\hline \multicolumn{4}{|l|}{ Biaya Keuangan } \\
\hline Biaya Selisih Kurs & $131.659 .556,36$ & - & $131.659 .556,36$ \\
\hline Biaya Bunga Pinjaman & $1.388 .661 .944,27$ & - & $1.388 .661 .944,27$ \\
\hline Biaya Administrasi Bank & $41.728 .718,50$ & - & $41.728 .718,50$ \\
\hline Total Biaya Keuangan & $1.562 .050 .219,13$ & - & $1.562 .050 .219,13$ \\
\hline TOTAL & 6.135.896.693,58 & 41.521.845.020,29 & 47.657.741.713,87 \\
\hline
\end{tabular}

Sumber: Data Sekunder yang diolah, 2018

dikomposisikan sebesar proporsi nilai jual untuk produk Baseball Gloves sebagai berikut:
Biaya Produksi

Biaya Upah Langsung

Biaya Bahan Packing

Biaya Upah \& THR Tak Langsung

Biaya Perlengkapan Bengke

Biaya Perlengkapan Kendaraan

Biaya Angkut/ Kirim/ Bongkar

Biaya Impor

Biaya Perlengkapan Produksi

Biaya Bord

Biaya BBM

Biaya Umum \& Administrasi

Biaya Karyawan Kantor

Biaya Perlengkapan Kantor

ya Komunikasi

Biaya Perlengkapan Kendaraan

Biaya Custom Guarantee

Biaya Asuransi Mobil

Total Biaya Umum \& Administrasi

Biaya Penjualan

Biaya Perjalanan Dina

Total Biaya Penjualan

$.388 .661 .944,27$

41.521.845.020,29

47.657.741.713 


\section{Pengalokasian Biaya Variabel}

Berikut merupakan pengalokasian biaya variabel per unit produk Baseball Gloves:

Tabel 5. Alokasi Biaya Variabel per unit produk Baseball Gloves

\begin{tabular}{|c|c|c|c|c|c|c|c|c|}
\hline No & Jenis Biaya & Easton (Rp) & Wilson (Rp) & IKJ (Rp) & $\operatorname{David}(\mathrm{Rp})$ & Buckler (Rp) & Franklin (Rp) & Bradley (Rp) \\
\hline 1 & Biaya Bahan Baku & $183.432,74$ & $326.883,03$ & $266.038,84$ & $313.940,67$ & $205.848,59$ & $147.732,60$ & $237.654,03$ \\
\hline 2 & Biaya Upah Langsung & $34.361,80$ & $61.233,83$ & $49.836,10$ & $58.809,38$ & $38.560,88$ & $27.674,22$ & $44.518,88$ \\
\hline 3 & BOP & $33.226,34$ & $59.210,40$ & $48.189,31$ & $56.866,07$ & $37.286,66$ & $26.759,75$ & $43.047,79$ \\
\hline 4 & Biaya Umum \& Administrasi & 628,01 & $1.119,14$ & 910,83 & $1.074,83$ & 704,75 & 505,79 & 813,65 \\
\hline 5 & Biaya Penjualan & $12.062,62$ & $21.495,98$ & $17.494,84$ & $20.644,88$ & $13.536,70$ & $9.714,96$ & $15.628,24$ \\
\hline & Total & 263.711,51 & $469.942,37$ & $382.469,91$ & $451.335,83$ & $295.937,58$ & $212.387,32$ & $341.662,58$ \\
\hline
\end{tabular}

Sumber: Data Sekunder yang diolah, 2018

Kontribusi Margin dan Rasio Besarnya kontribusi margin pada PT Kontribusi Margin pada PT Inko Java Inko Java Semarang per unit produk Semarang

Baseball Gloves adalah:

Tabel 6. Kontribusi Margin per unit produk Baseball Gloves

\begin{tabular}{|c|c|c|c|c|c|c|c|}
\hline \multirow{2}{*}{$\frac{\text { No }}{1}$} & \multirow{2}{*}{$\begin{array}{l}\text { Nama Produk } \\
\text { Easton }\end{array}$} & \multicolumn{2}{|c|}{ Harga Jual/ Unit } & \multicolumn{2}{|c|}{$\begin{array}{c}\text { Biaya Variabel/ } \\
\text { Unit }\end{array}$} & \multicolumn{2}{|c|}{$\begin{array}{c}\text { Kontribusi } \\
\text { Margin/ Unit }\end{array}$} \\
\hline & & $\mathrm{Rp}$ & 299.333 & $\mathrm{Rp}$ & $263.711,51$ & $\mathrm{Rp}$ & $35.621,91$ \\
\hline 2 & Wilson & $\mathrm{Rp}$ & 533.422 & $\mathrm{Rp}$ & $469.942,37$ & $\mathrm{Rp}$ & $63.479,38$ \\
\hline 3 & $\mathrm{IKJ}$ & $\mathrm{Rp}$ & 434.134 & $\mathrm{Rp}$ & $382.469,91$ & $\mathrm{Rp}$ & $51.663,69$ \\
\hline 4 & David & $\mathrm{R}_{\mathrm{H}}$ & 512.302 & $\mathrm{Rp}$ & $451.335,83$ & $\mathrm{Rp}$ & $60.966,03$ \\
\hline 5 & Buckler & $\mathrm{Rp}$ & 335.913 & $\mathrm{Rp}$ & $295.937,58$ & $\mathrm{Rp}$ & $39.974,98$ \\
\hline 6 & Franklin & $\mathrm{Rp}$ & 241.076 & $\mathrm{Rp}$ & $212.387,32$ & $\mathrm{Rp}$ & $28.689,08$ \\
\hline 7 & Bradley & $\mathrm{Rp}$ & 387.814 & $\mathrm{Rp}$ & $341.662,58$ & $\mathrm{Rp}$ & $46.151,47$ \\
\hline
\end{tabular}

Sumber: Data Sekunder yang diolah, 2018

Bagi perusahaan yang memiliki lebih dari satu produk, kontribusi margin yang digunakan adalah kontribusi

margin rata-rata per unit produk. Perhitungan kontribusi margin ratarata dapat dilihat pada tabel berikut:

Tabel 7. Kontribusi Margin Rata - rata produk Baseball Gloves

\begin{tabular}{|c|c|c|c|c|c|c|c|c|c|c|c|}
\hline \multirow[t]{2}{*}{ No } & Nama Produk & Sales Mix (Unit) & \multicolumn{2}{|c|}{ Harga Jual/Unit } & $\begin{array}{c}\text { Biaya Variabel/ } \\
\text { Unit }\end{array}$ & \multicolumn{2}{|c|}{ Proporsi Penjualan } & \multicolumn{2}{|c|}{ Proporsi Biaya Variabel } & \multicolumn{2}{|c|}{$\begin{array}{l}\text { Kontribusi Margin Rata- } \\
\text { rata }\end{array}$} \\
\hline & 1 & 2 & & 3 & 4 & & $5=2 \times 3$ & & & & $5 \cdot 6$ \\
\hline 1 & Easton & $72,86 \%$ & $\mathrm{Rp}$ & 299.333 & Rp 263.711,51 & $\mathrm{Rp}$ & $218.097,79$ & $\mathrm{Rp}$ & $192.143,25$ & $\mathrm{Rp}$ & $25.954,53$ \\
\hline 2 & Wilson & $13,66 \%$ & $\mathrm{Rp}$ & 533.422 & Rp $\quad 469.942,37$ & $\mathrm{Rp}$ & $72.844,81$ & $\mathrm{Rp}$ & $64.175,98$ & $\mathrm{Rp}$ & $8.668,83$ \\
\hline 3 & IKJ & $8,08 \%$ & $\mathrm{Rp}$ & 434.134 & Rp $382.469,91$ & $\mathrm{Rp}$ & $35.084,05$ & $\mathrm{Rp}$ & $30.908,90$ & $\mathrm{Rp}$ & $4.175,15$ \\
\hline 4 & David & $1,81 \%$ & $\mathrm{Rp}$ & 512.302 & Rp 451.335,83 & $\mathrm{Rp}$ & $9.280,15$ & $\mathrm{Rp}$ & $8.175,77$ & $\mathrm{Rp}$ & $1.104,38$ \\
\hline 5 & Buckler & $1,25 \%$ & $\mathrm{Rp}$ & 335.913 & Rp 295.937,58 & $\mathrm{Rp}$ & $4.186,63$ & $\mathrm{Rp}$ & $3.688,40$ & $\mathrm{Rp}$ & 498,23 \\
\hline 6 & Franklin & $1,52 \%$ & $\mathrm{Rp}$ & 241.076 & Rp $\quad 212.387,32$ & $\mathrm{Rp}$ & $3.667,22$ & $\mathrm{Rp}$ & $3.230,81$ & $\mathrm{Rp}$ & 436,41 \\
\hline 7 & Bradley & $0,82 \%$ & $\mathrm{Rp}$ & 387.814 & Rp $341.662,58$ & $\mathrm{Rp}$ & $3.189,08$ & $\mathrm{Rp}$ & $2.809,57$ & $\mathrm{Rp}$ & 379,51 \\
\hline & $\begin{array}{l}\text { ibusi Rata-rata } \\
\text { iit }\end{array}$ & & & & & Rp & $346.349,72$ & Rp & $305.132,68$ & $\mathrm{Rp}$ & $41.217,04$ \\
\hline
\end{tabular}


Sedangkan rasio kontribusi margin adalah persentase kontribusi margin yang dapat digunakan untuk menutup biaya tetap. atas penjualan. Rasio margin kontribusi menunjukkan persentase

$$
\begin{aligned}
& \text { Rasio Margin Kontribusi } \\
& =\frac{\text { Margin Kontribusi Rata-rata per Unit }}{\text { Total Penjualan Rata-rata }} \times 100 \% \\
& \text { Rasio Margin Kontribusi }
\end{aligned}
$$

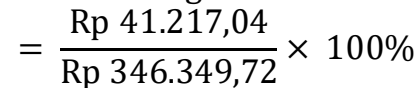

Titik Impas pada PT Inko Java risiko dan ketidakpastian kondisi

\section{Semarang}

Titik Impas adalah suatu titik dimana total biaya yang dikeluarkan dengan total penjualan besarnya adalah sama.

Dari perhitungan kontribusi margin diatas, maka dapat diketahui titik impas baik dalam rupiah maupun unit. Perhitungan Titik Impas dalam unit pada PT Inko Java Semarang Tahun 2017 sebagai berikut:

Titik Impas (Unit)

$$
\begin{aligned}
& =\frac{\text { Margin Kontribusi Rata }- \text { rata per unit }}{\text { Rp 6.135.896.693,58 }} \\
& \text { Titik Impas (Unit) }=\frac{\text { Rp 41.217,04 }}{\text { Titik Impas (Unit) }=148.868}
\end{aligned}
$$

Berikut perhitungan titik impas dalam rupiah penjualan pada PT Inko Java Semarang Tahun 2017:

Titik Impas (Rupiah)

$$
=\frac{\text { Biaya Tetap Total }}{\text { Rasio Margin Kontribusi }}
$$

Titik Impas (Rupiah)

$$
=\frac{\operatorname{Rp} 6.135 .896 .693,58}{11,90 \%}
$$

Titik Impas (Rupiah)

$$
=\operatorname{Rp} 51.560 .373 .141,52
$$

Berdasarkan perhitungan diatas diketahui titik impas PT Inko Java Semarang berasa pada tingkat penjualan 148.868 unit dengan nilai penjualan Rp51.560.373.141,52.

\section{Batas Pengaman(Margin of Safety) pada PT Inko Java Semarang tahun 2017}

Batas pengaman merupakan salah satu upaya dalam menghadapi bisnis di masa depan. Analisa ini bertujuan untuk memberikan informasi mengenai sejauh mana penjualan boleh turun agar tidak merugikan perusahaan.

Perhitungan batas pengaman dalam rupiah pada PT Inko Java Semarang tahun 2017 adalah sebagai berikut:

Batas Pengaman (Rp)

$=$ Penjualan Aktual - Penjualan Impas

Batas Pengaman (Rp)

$=\mathrm{Rp} \quad 47.130 .577 .833,00 \quad-\mathrm{Rp}$

51.560.373.141,52

Batas Pengaman (Rp)

$=-\operatorname{Rp} 4.429 .795 .308,52$

Perhitungan batas pengaman dalam unit pada PT Inko Java Semarang tahun 2017 adalah sebagai berikut:

Batas Pengaman (Unit)

$=$ Penjualan Aktual - Pejualan Impas

Batas Pengaman (Unit)

$=136.078-148.868$

Batas Pengaman $($ Unit $)=-12.790$ unit

Perhitungan persentase batas pengaman pada PT Inko Java tahun 2017 adalah sebagai berikut:

$\%$ Batas Pengaman

$=\frac{\text { Batas Keamanan (Rp) }}{\text { Total Penjualan Aktual (Rp) }} \times 100 \%$

\% Batas Pengaman

$=\frac{(\operatorname{Rp~4.429.795.308,52)}}{\operatorname{Rp~47.130.577.833,00}} \times 100 \%$

$\%$ Batas Pengaman $=-9,40 \%$

Berdasarkan perhitungan di atas, dapat diketahui tingkat batas pengaman sebesar $(9,40 \%)$. Hal ini berarti bahwa pada tahun 2017 PT Inko Java Semarang tidak mampu mencapai penjualan impas, terlihat dari penjualan yang turun sebesar 
12.790 unit atau sebesar $\mathrm{Rp}$ 4.429.795.308,52 dibawah titik impas.

\section{Tingkat Pengungkit Operasi (Degree of Operating Leverage) pada PT Inko Java Semarang tahun 2017}

Selain batas keamanan, pengungkit operasi juga merupakan salah satu upaya dalam menghadapi risiko dan ketidakpastian kondisi bisnis di masa depan. Pengungkit operasi bertujuan memberikan informasi mengenai pengaruh perubahan persentase volume penjualan terhadap laba. Tingkat pengungkit operasi pada PT Inko Java Semarang tahun 2017 dapat dihitung sebagai berikut:

Tingkat Pengungkit Operasi

$=\frac{\text { Margin Kontribusi }}{\text { Laba Neto }}$

Tingkat Pengungkit Operasi

$=\frac{\operatorname{Rp} 5.608 .732 .812,71}{-\operatorname{Rp} 527.163 .880,48}$

Tingkat Pengungkit Operasi $=-10,64$

Berdasarkan perhitungan diatas dapat diketahui bahwa pada tahun 2017, setiap $\mathrm{Rp} 1$ penjualan menanggung kerugian sebesar $\mathrm{Rp}$ 10,64 .

\section{Titik Penutupan Usaha (Shut Down Point) pada PT Inko Java Semarang} Titik penutupan usaha merupakan kondisi dimana kontribusi margin hanya mampu diguanakan untuk menutup sebagian dari biaya tetap perusahaan yaitu biaya tetap tunai perusahaan. Perhitungan Shut Down Point pada PT Inko Java Semarang tahun 2017 adalah sebagai berikut:

Shut Down Point (Rp)

Biaya Tetap Tunai

$=\overline{\text { Rasio Kontribusi Margin Rata - rata per Unit }}$ Shut Down Point (Rp)

$=\frac{\operatorname{Rp} 5.453 .237 .479,76}{11,90 \%}$

Shut Down Point (Rp)

$=\operatorname{Rp} 45.823 .939 .568,56$

Berdasarkan perhitungan

diatas, titik penutupan usaha (Shut Down Point) PT Inko Java Semarang berada pada tingkat penjualan $\mathrm{Rp}$ 45.823.939.568,56 atau sebesar 132.305 unit. Pada tahun 2017 tingkat penjualan PT Inko Java Semarang sedikit di atas titik penutupan usaha yaitu $R p$ 47.130.577.833 atau sebesar 136.078 unit. Oleh karena itu, diharapkan PT Inko Java Semarang dapat meningkatkan penjualannya sehingga dapat terus melanjutkan usahanya.

\section{Kondisi Perusahaan Tahun 2017}

Pada tahun 2017, perusahaan mengalami kerugian sebesar $\mathrm{Rp}$ 527.163.880,48. Diketahui total penjualan tahun 2017 sebesar $R p$ 47.130.577.833 berada dibawah titik impas yaitu sebesar $\mathrm{Rp}$ 51.560.373.141,52 dan sedikit berada diatas titik penutupan usaha sebesar Rp 45.823.939.568,56.

Aplikasi Biaya Volume Laba sebagai Perencanaan Laba pada PT Inko Java Semarang

Aplikasi biaya volume laba merupakan alat yang berguna dalam melakukan perencanaan laba. Perencanaan laba pada dasarnya merupakan acuan yang digunakan manajemen dalam menjalankan kegiatan usahanya untuk mencapai tujuan perusahaan, yaitu memperoleh laba. Sepeti yang diketahui, pada tahun 2017 perusahaan sempat mengalami kerugian. Oleh sebab itu, perusahaan harus melakukan perencanaan laba agar kerugian tidak terjadi lagi, sehingga perusahaan menjadi termotivasi dalam meningkatkan penjualannya. Laba yang ditargetkan perusahaan adalah sebesar 1\% dari penjualan tahun 2017. Perhitungan target laba pada PT Inko Java Semarang adalah sebagai berikut: Unit Penjualan untuk mencapai Target Laba $=\frac{\text { Target Laba }+ \text { Biaya Tetap }}{\text { Margin Kontribusi Rata }- \text { rata per Unit }}$ Unit Penjualan untuk mencapai Target Laba $=\frac{(1 \% \times \operatorname{Rp~47.130.577.833)~}+\mathrm{Rp} 6.135 .896 .693,58}{\operatorname{Rp} 41.217,04}$

Unit Penjualan untuk mencapai Target Laba $=\frac{\operatorname{Rp} 471.305 .778,33+\operatorname{Rp} 6.135 .896 .693,58}{\operatorname{Rp} 41.217,04}$ 
Unit Penjualan untuk mencapai Target Laba $=\frac{\operatorname{Rp} 6.607 .202 .471,91}{\operatorname{Rp} 41.217,04}$

Unit Penjualan untuk mencapai Target Laba $=160.303$ unit (Pembulatan dari 160.302,69209)

\section{Batas Pengaman (Margin Of Safety) PT Inko Java Semarang}

Batas Pengaman memberikan informasi mengenai seberapa besar penjualan diperbolehkan mengalami penurunan dari penjualan yang dianggarkan namun tidak merugikan perusahaan.

Perhitungan batas pengaman dalam rupiah pada PT Inko Java Semarang adalah sebagai berikut:

Batas Pengaman (Rp)

$=$ Penjualan yang Dianggarkan -

Penjualan Impas

Batas Pengaman (Rp)

$=\mathrm{Rp} 55.520 .899 .913,00-\mathrm{Rp}$

51.560.373.141,52

Batas Pengaman (Rp)

$=$ Rp 3.960.526.771,48

Perhitungan batas pengaman dalam unit pada PT Inko Java Semarang adalah sebagai berikut:

Batas Pengaman (Unit)

$=$ Penjualan yang Dianggarkan -

Pejualan Impas

Batas Pengaman (Unit)

$=160.303-148.868$

Batas Pengaman (Unit) $=11.435$ unit

Perhitungan persentase margin pengaman dalam rupiah pada PT Inko Java Semarang adalah sebagai berikut: $\%$ Batas Pengaman

$=\frac{\text { Batas Keamanan }(\mathrm{Rp})}{\text { Total Penjualan yang Dianggarkan }(\mathrm{Rp})}$

$\%$ Batas Pengaman

$=\frac{\operatorname{Rp~3.960.526.771,48}}{\operatorname{Rp~55.520.899.913,00}}$

$\%$ Batas Pengaman

$=0,07133$ atau $7,13 \%$

Dari perhitungan diatas, dapat ditarik kesimpulan bahwa batas maksimal terjadi penurunan penjualan agar tidak mengalami kerugian adalah sebesar Rp3.960.526.771,48 atau sebesar $7,13 \%$ apabila penjualan yang dianggarkan tidak dapat tercapai.
Tingkat Pengungkit Operasi (Degree of Operating Leverage) pada PT Inko Java Semarang

Pengungkit operasi bertujuan memberikan informasi mengenai pengaruh perubahan persentase volume penjualan terhadap laba. Tingkat pengungkit operasi pada PT Inko Java Semarang dapat dihitung sebagai berikut:

Tingkat Pengungkit Operasi

$=\frac{\text { Kontribusi Margin }}{\text { Laba Neto }}$

Tingkat Pengungkit Operasi

$=\frac{\operatorname{Rp~5.608.732.812,71~}}{\operatorname{Rp~471.305.778,33}}$

Tingkat Pengungkit Operasi $=11,90$

Tingkat pengungkit operasi pada PT Inko Java Semarang adalah sebesar 13,82. Hal ini berarti bahwa setiap terjadi perubahan penjualan sebesar $1 \%$ maka laba akan meningkat sebesar $11,90 \%$.

Titik Penutupan Usaha (Shut Down Point) pada PT Inko Java Semarang

Titik penutupan usaha merupakan kondisi dimana pendapatan penjualan perusahaan setelah dikurangi biaya variabel (kontribusi margin) hanya mampu menutup biaya tetap tunai. Seperti yang telah dibahas sebelumnya, diketahui bahwa titik penutupan usaha (Shut Down Point) pada PT Inko Java adalah sebesar 132.305 unit atau senilai $\mathrm{Rp}$ 45.823.939.568,56. Oleh karena itu diharapkan agar PT Inko Java dapat melakukan penjualan diatas titik penutupan usaha karena apabila perusahaan hanya dapat mencapai tingkat penjualan sebesar titik penutupan, maka perusahaan tidak mampu untuk menutup biaya tetap non tunainya.

\section{KESIMPULAN}

Berdasarkan analisis yang telah dilakukan mengenai hubungan biaya, volume, dan laba sebagai alat dalam perencanaan laba pada PT Inko Java Semarang, maka dapat diambil kesimpulan sebagai berikut:

a) Perusahaan belum pernah menerapkan analisis biaya volume 
laba dalam melakukan perencanaan laba sehingga perencanaan laba yang dilakukan belum secara detail. Oleh karena itu perusahaan belum dapat merancang tingkat penjualan yang diinginkan untuk mencapai tingkat laba yang dianggarkan.

b) Berdasarkan analisis biaya volume laba yang dilakukan, laba yang dianggarkan adalah sebesar $1 \%$ dari penjualan tahun 2017 atau sebesar Rp471.305.778,33 sehingga penjualan yang harus dilakukan untuk mencapai laba yang dianggarkan adalah sebesar $\mathrm{Rp}$ 55.520.899.913.

PT Inko Java Semarang diharapkan dapat menerapkan analisis biaya volume laba dalam merencanakan laba agar perusahaan bisa memperoleh laba secara terukur dan tidak mengalami kerugian. Analisis ini membantu perusahaan untuk mengetahui seberapa banyak penjualan yang harus dilakukan agar dapat membiayai biaya yang dikeluarkan dan mencetak laba.

\section{DAFTAR PUSTAKA}

Arizal, M Fatqurrodji et al. 2014. " Analisis Cost Volume Profit Sebagai Dasar Perencanaan Penetapan Harga Jual dan Perencanaan Laba yang Diharapkan. (Study Pada Perusahaan Sumber Agung Kec. Sukun Kota Malang Periode 2013)". Jurnal Administrasi Bisnis (JAB). Volume 13, Nomor 2, Malang.

Budiwibowo, Satrijo. 2012. "Analisis Estimasi Cost-Volume-Profit (CVP) Dalam Hubungannya Dengan Perencanaan Laba Pada Hotel Tlogo Mas Sarangan". Jurnal Akutansi dan Pendidikan. Volume 1, Nomor 1, Madiun.

Bungin, Burhan. 2013. Metodologi Penelitian Sosial \& Ekonomi. Jakarta: Kencana.
Garrison, Ray H et al. 2013. Akuntansi Manajerial Buku I. Jakarta: Salemba Empat.

Hansen, Don $\mathrm{R}$ dan Marryanne $\mathrm{M}$ Mowen. 2009. Akuntansi Manajerial Buku II. Jakarta: Salemba Empat.

Horngren, Charles et al. 2006. Akuntansi Biaya Penekanan Manajerial Jilid I. Jakarta: Erlangga.

Iswara, Ulfah Setia dan Susanti. 2017. "Analisis Cost Volume Profit Sebagai Dasar Perencanaan Laba Yang Diharapkan (Studi Pada Perusahaan Kopi Di Kabupaten Jember)". Jurnal RAK (Riset Akuntansi Keuangan). Volume 2, Nomor 3, Surabaya.

Jusup, Haryono. 2011. Dasar-dasar Akuntansi Jilid I. Yogyakarta: STIE YKPN.

Keraf, Gorys. 2004. Komposisi. Ende Flores: Nusa Indah.

Kusuma, Hadri el al. 2013. Akuntansi Manajemen.

Yogyakarta:

Ekonisia.

Lam, Nelson dan Peter Lau. 2014. Akuntansi Keuangan: Intermediate Financial Reporting Buku I. Jakarta: Salemba Empat.

Narbuko, Cholid dan H. Abu Achmadi. 2012. Metodologi Penelitian. Jakarta: Bumi Aksara.

Salman, Kautsar Riza dan Mochammad Farid. 2016. Akuntansi Manajemen: Alat Pengukuran dan Pengambilan Keputusan Manajerial. Jakarta: Permata Putri Media. 
Samryn, L.M. 2012. Akuntansi Manajemen: Informasi Biaya untuk Mengendalikan Aktivitas Operasi \& Investasi. Jakarta: Kencana.

Simamora, Henry. 2012. Akuntansi Manajemen. Riau: Star Gate Publisher.

Siregar, Baldric et al. 2013. Akuntansi Manajemen. Jakarta: Salemba Empat.
Suliyanto. 2006. Metode Riset Bisnis.Yogyakarta: Andi.

Supriyono, R.A. 2008. Akuntansi Biaya: Perencanaan dan Pengendalian Biaya Serta Pembuatan Keputusan Buku II. Yogyakarta: BPFE. 